http://jmscr.igmpublication.org/home/ ISSN (e)-2347-176x ISSN (p) 2455-0450 crossref DOI: https://dx.doi.org/10.18535/jmscr/v8i8.09

\title{
Influence of Management Practices on Service Delivery in Public Sub- County Hospitals in Meru County
}

\author{
Authors \\ Jason Maingi Anampiu ${ }^{\&}$, Wanja Mwaura-Tenambergen ${ }^{1}$, Roselynn Kinyamu \\ ${ }^{1}$ Department of Health Systems Management, Kenya Methodist University \\ ${ }^{2}$ Lecturer, School of Business, Riara University \\ *Corresponding Author \\ Jason Maingi Anampiu
}

\begin{abstract}
Introduction: Integrated and people-centred health services are critical for realizing universal health care coverage. This can only be achieved through provision of efficient and effective health services. Service delivery is one of the key building blocks of any health system; it is an immediate output of the inputs into the health system, such as the health workforce, procurement and supplies, infrastructure and financing. The rising burden of disease and weak health systems are being compounded by the poor health service delivery. The purpose of the study was to determine the influence of management practices on service delivery in sub-county hospitals in Meru County.

Methods: The study adopted a descriptive cross-sectional design. The target population consisted of five officers from each of the 23 sub-county hospitals which total up to 115. Open and closed ended questionnaires were used to collect data. The raw data was-generated and entered in an Epidata and SPSS version 22.0 for management.

Results: The study found that management practices had significant influence on service delivery at SubCounty Hospitals in Meru County. This study recommended that management should follow and adhere to hospital plans, motivation policy and lead by example to ensure smooth service delivery to the patients. Keywords: Service delivery, Health care, Sub-county Hospitals.
\end{abstract}

\section{Introduction}

Integrated and people-centred health services are critical for realizing universal health care coverage. This can only be achieved through provision of efficient and effective health services. Service delivery is one of the key building blocks of any health system, it is an immediate output of the inputs into the health system, such as the health workforce, procurement and supplies, infrastructure and financing. Adequate provision of inputs should lead to enhanced service delivery and access to services. Ensuring availability of health services that meet a minimum quality standard and securing access to them are key functions of a health system (WHO 2010). According to WHO (2007), good health services are those which deliver effective, safe, quality personal and non-personal health interventions to those who need them, when and where needed, with minimum waste of resources. A service is a process consisting of a series of more or less intangible activities that normally, 
but not necessarily always, that take place in interactions between the customer and service employee and/or physical resources or goods and/or systems of the service provider, which are provided as solutions to customer problems (Grönroos, 2007). Moreover, service is seen as any act or performance one party can offer to another that is essentially intangible and does not result in the ownership of anything (Kotler \& Keller, 2009).

Kim (2012) defines service delivery as a series of highly localized actions by agents in public agencies or private enterprises to provide needed goods and services to citizen beneficiaries in a way that meets their expectations. Service delivery has a life-cycle span (i.e. plan, design, operate, maintain, and monitor) to sustain services such as nutrition or transport or goods such as electricity or water to citizen beneficiaries (Kim 2012; Lockwood and Smits 2011). Getting (or delivering) these services or goods requires access by citizen beneficiaries, and the goods or services should meet the expectations of the beneficiaries, which implies taking into account their needs and demands (Kim 2012; Hodge 2007; Fiszbein, Ringold, and Rogers 2011).

According to WHO (2010), service delivery to patients includes provision of health services at all levels as per the standard which include speed of delivery, harmonization at service delivery point, effectiveness of the services, patient safety, ethics and professionalism in during provision of service. To better understand the degree of service delivery, there is need to understand customer satisfaction because the level of service delivery and quality of service are mainly related to customer satisfaction. Customer satisfaction is a person's feeling of pleasure or disappointment resulting from and coverage of health care services.

Enderson (2016) notes that hospitals' service delivery in Africa faces difficult challenges such as shortage of health workers, increased caseloads for health workers due to migration of skilled health personnel and the double burden of disease and the HIV/AIDS scourge that affect both the general population and health personnel, shortage/low motivation of health workers. Moreover, Mahapatro, (2010) agrees that inappropriate quality of service delivery results in loss of customer lives, revenue, material resources, time, morale, staff, recognition, trust and respect and individual and communities' apathy towards health services, all of which contribute to lowered effectiveness and efficiency of service provider.

According to WHO (2013) any country that has unhealthy population bounds to suffer in the implementation of development program to improve the quality life of its citizens. Andaleeb (2015) suggests that each country needs to offer quality health services and it is important to recognize that a healthy population is better disposed to achieving the productivity that is needed so as to increase and sustain continued growth of the country's economy.

The Kenyan health service delivery system is organized into 6 levels of care that fits into four tiers. Each level has specified scope health services that it should provide to its populace. Tier 1 community units, Tier 2 dispensaries and health Centres, Tier 3 County health facilities (Sub County and County referral hospital) and Tier 4 national referrals (John Njuguna, 2014). Health services are provided through a network of over 4,700 health facilities countrywide, with the public sector system accounting for about 51 percent of these facilities while 49 percent is accounted for by the private sector. The public health sector consists of the national referral hospitals, county referral hospitals, Sub-county hospitals, health centres, and dispensaries. Health services are integrated as one goes down the hierarchy of health structure from the national level to the county levels (Chodzaza \& Gombachika, 2013).

Meru County is one of the 47 counties of Kenya strategically located east of Mt. Kenya, whose peak cuts through the outskirt of its southern boundary. The county has a total area of 
$6,936.2 \mathrm{Km}^{2}$ out of which $972.3 \mathrm{Km}^{2}$ is gazetted forest. Health services provision at the County level is centred around the tenets described by both the Kenya Essential Package of Health Services (KEPHS) and Schedule IV of the Kenya Constitution 2010. These two key documents define mandates/roles/responsibilities for interventions and service delivery of the health system. The county has 23 sub-county hospitals and one referral hospital (Meru County Data, 2017).

In Kenya health is anchored in Vision 2030 under social pillar in which the country's aim is to provide an efficient integrated and high quality affordable health care for all citizens with a priority being given to preventive care at the community and household levels using a decentralized national health care system strategy (GoK, 2007). The health policy 2014-2030 spells out the organization of health services delivery system and what should be provided at the specific hospitals, geared towards strengthening the referral mechanism in place (John Njuguna, 2014). The Sub-County health facilities (Levels 4) managed by the county governments are mandated to: offer comprehensive patient diagnostic, medical, surgical and rehabilitative care, including reproductive health services, specialized outpatient services, and facilitate and manage referrals from lower levels to other levels (Ministry of Health, 2014).

Despite this, patients still prefer accessing services from the county referral hospital (Level 5) due to numerous challenges at the Sub-county hospitals. A study done by Makheti, (2017) reveals that Sub-county hospitals in Meru lacked equipment and drugs forcing health workers to rely on conventional diagnosis further putting patients in danger of misdiagnosis. Another report by the Ministry of Health in 2013 on service availability and readiness assessment mapping, showed that the county hospitals offered a higher percentage of services e.g. pharmaceuticals, clinical laboratory, and maternity which accounted for $70 \%, 85 \%$ and $74 \%$ respectively (Government of Kenya, 2013).

This has caused an increased and continued congestion and strain on the county referral hospital thus hampering quality of care. Despite the tremendous efforts by the government to improve the referral system in Kenya in order to improve efficiency in the health system and health outcomes, service delivery remain a big challenge impeding access to equitable, quality and responsive health services by the populace equity quality services. Should the problem of underutilization health services in the Sub-county hospitals continue, the county and the country at large might not be able to achieve its health goal of attaining the highest standards of health by the year 2030 (John Njuguna, 2014). A need therefore arises to investigate whether the Sub-county hospitals in Meru County are delivering services commensurate to the concerted effort by the county government to provide cost-effective priority healthcare interventions and services to ensure affordable, equitable, accessible and acceptable health services. Therefore, this study sought to determine the influence of management practices on service delivery in sub-county hospitals in Meru County.

\section{Objective of the study}

The objective of the study was to determine the influence of management practices on service delivery in sub-county hospitals in Meru County.

\section{Methodology}

The study adopted a descriptive cross-sectional design and was carried out in Meru County. Meru County is one of the 47 counties of Kenya strategically located east of Mt. Kenya. The county has a total area of $6,936.2 \mathrm{Km}^{2}$. The county borders five counties; to the North it borders Isiolo County, to the East Tharaka/Nithi County, to the South West Nyeri County and to the West Laikipia County. The county's' administrative structure comprises of 9 sub-counties where target population consisted of health officers from 23 
Sub-county hospitals. The total number of respondents was 115 . The respondents were purposively selected based on the their job positions, specialized knowledge, capacity and understanding of health matters under this study. Data was collected by use of a questionnaire that contained structured questions. Data was analyzed using SPSS version 23 and presented through descriptive and inferential statistics. Ethical clearance was obtained from the Ethics and Research Committee of Kenya Methodist
University and permission sought from the respective hospital administrations. All respondents were informed the purpose of the study and they signed an informed consent form.

\section{Results}

Demographic Characteristics of the respondent There were 84 respondents who participated in the survey. Table 1 shows the socio-demographic characteristics of the respondents.

Table 1 Demographic Characteristics of the respondent $(\mathrm{N}=84)$

\begin{tabular}{|l|c|c|c|}
\hline Demographic Information & Variable & Frequency (n) & Percentage (\%) \\
\hline Gender & Male & 35 & 41.7 \\
\hline Age & Female & 49 & 58.3 \\
\hline & $21-30$ Years & 42 & 50.0 \\
\hline & $31-40$ Years & 13 & 15.5 \\
\hline & $41-50$ Years & 19 & 22.6 \\
\hline Education Level & $51-60$ Years & 10 & 11.9 \\
\hline & Certificate & 5 & 6.0 \\
\hline & Diploma & 52 & 61.9 \\
\hline & Bachelor & 23 & 27.4 \\
\hline & Masters & 1 & 1.2 \\
\hline & PhD & 1 & 1.2 \\
\hline Years Worked & Other & 2 & 2.3 \\
\hline & $0-5$ & 55 & 64.9 \\
\hline & $6-11$ & 17 & 20.1 \\
\hline & $11-15$ & 3 & 3.6 \\
\hline & $16-20$ & 2 & 2.4 \\
\hline & $21-30$ & 7 & 9.0 \\
\hline
\end{tabular}

Majority of the respondents $(n=49,58.3 \%)$ were female while $(n=35,41.7 \%)$ were male. Which indicated a fair participation and response as well as balanced gender as far as employment in subcounty hospitals is concerned. In level of education, majority of the respondents had a diploma and above implying that these officers were well educated and therefore could understand issues concerning hospitals as well as this study.

\section{Respondents' Opinion on Service Delivery}

Respondents were asked to respond to the set of questions related to service delivery at SubCounty Hospitals in Meru County, Kenya. The results in Table 2 show that respondents agreed that managers are allocated the necessary authority to achieve planned objectives and held accountable for overall performance and results mean score of 3.82 , services may be provided in the home, the community, the workplace, or health facilities as appropriate mean of 3.82, hospital services are effective in serving patients' needs mean of 3.61, and services are directly and permanently accessible with no undue barriers of cost, language, culture, or geography means score of 3.55 . 
Table 2 Respondents' Opinions on Service Delivery

\begin{tabular}{|l|c|c|c|}
\hline Statements & N & Mean & Std. Dev. \\
\hline Hospital services are effective in serving patients' needs & 84 & 3.61 & .932 \\
\hline Services offered in this hospital are safe to the patients & 84 & 3.40 & .778 \\
\hline Services offered here are centered on the patient's needs & 84 & 3.58 & .867 \\
\hline $\begin{array}{l}\text { Health services are well managed so as to achieve the core elements } \\
\text { described above with a minimum wastage of resources }\end{array}$ & 84 & 2.80 & .636 \\
\hline $\begin{array}{l}\text { Managers are allocated the necessary authority to achieve planned } \\
\text { objectives and held accountable for overall performance and results }\end{array}$ & 84 & 3.82 & 1.153 \\
\hline Health services are delivered in a timely manner to the patients & 84 & 3.36 & .801 \\
\hline $\begin{array}{l}\text { Services are directly and permanently accessible with no undue barriers } \\
\text { of cost, language, culture, or geography }\end{array}$ & 84 & 3.55 & .870 \\
\hline $\begin{array}{l}\text { Health services are close to the people, with a routine point of entry to } \\
\text { the service network at primary care level }\end{array}$ & 84 & 2.77 & .588 \\
\hline $\begin{array}{l}\text { Services may be provided in the home, the community, the workplace, or } \\
\text { health facilities as appropriate }\end{array}$ & 84 & 3.82 & 1.153 \\
\hline
\end{tabular}

However, respondents disagreed that health services are well managed so as to achieve the core elements described above with a minimum wastage of resources means of 2.80 , health services are close to the people with a routine point of entry to the service network at primary care level 2.77, and health services are delivered in a timely manner to the patients means score of 3.36. From the responses of the respondents it was evident that "Managers are allocated the necessary authority to achieve planned objectives and held accountable for overall performance and results and Services may be provided in the home, the community, the workplace, or health facilities as appropriate" were good indicators of service delivery. This is because these two attributes of service delivery received the highest mean (Mean= 3.82; $\mathrm{SD}=1.153$ and Mean=3.82; $\mathrm{SD}=1.153$ respectively). This meant that there was proper service delivery in all sub-county Hospitals in Meru County.

\section{Management Practices in Sub-county Hospitals of Meru County}

The study findings show that on average the respondents agreed that the management practices have an influence on service delivery in subcounty hospitals in Meru County. The respondents agreed that management supervises staff adequately mean of 3.86 , management has various reward systems for motivating employees mean score of 3.85, there is sound relationship between staff and supervisors 3.62, resources are availed for implementing plans mean score of 3.55 , and that the hospital has a motivation policy for staff mean score of 3.54. They however disagreed that adequate resources are budgeted for implementing plans mean of 3.37, management follows and adhere to hospital plans mean of 2.76 , supervisors lead by examples to staff 3.38 , and that the hospital management follows and adheres to motivation policy 2.79 .

\section{Management Practices in Sub-county Hospitals of Meru County}

The study sought to determine the influence of management practices on service delivery in subcounty hospitals in Meru County. Table 3presents the results. The study findings show that on average the respondents agreed that the management practices have an influence on service delivery in sub-county hospitals in Meru County. The respondents agreed that management supervises staff adequately mean of 3.86 ; SD 1.121 , management has various reward systems for motivating employees mean score of 3.85; SD 1.146 , there is sound relationship between staff and supervisors 3.62; SD 0.675, resources are availed for implementing plans mean score of 3.55; SD 0.827, and that the hospital has a motivation policy for staff mean score of 3.54; 0.884. They however disagreed that adequate resources are budgeted for implementing plans mean of 3.37 , management follows and adhere to 
hospital plans mean of 2.76 , supervisors lead by examples to staff 3.38 , and that the hospital management follows and adheres to motivation policy 2.79 .

Table 3: Responses on Hospitals' Management Practices in Meru County

\begin{tabular}{|l|c|c|c|}
\hline Statements & $\mathbf{N}$ & Mean & Std. Dev. \\
\hline Adequate resources are budgeted for implementing plans & 84 & 3.37 & .788 \\
\hline Resources are availed for implementing plans & 84 & 3.55 & .827 \\
\hline Management follows and adhere to hospital plans & 84 & 2.76 & .652 \\
\hline Management supervises staff adequately & 84 & 3.86 & 1.121 \\
\hline There is sound relationship between staff and supervisors & 84 & 3.62 & .675 \\
\hline Supervisors lead by examples to staff & 84 & 3.38 & .805 \\
\hline Hospital has a motivation policy for staff & 84 & 3.54 & .884 \\
\hline Hospital management follows and adheres to motivation policy & 84 & 2.79 & .678 \\
\hline Management has various reward systems for motivating employees & 84 & 3.85 & 1.146 \\
\hline
\end{tabular}

\section{Correlation Analysis: Relationship between Independent and Dependent Variables}

The study put into use Karl pearsion correlation (r) with the intention of establishing the relationship between the independent variables and dependent variable. The results show that there is a strong and positive association between independent variable (management practices) and dependent variable (service delivery). From the correlation analysis, the results show that the coefficient of correlation of management practices showed $(\mathrm{r}=0.891, \mathrm{p}=0.001)$. This shows that there was a strong and positive association between independent variable (management practices) and service delivery at Sub-County Hospitals in Meru County, Kenya.

\section{Discussion}

Results on the respondents' opinion on service delivery found that there was proper service delivery in all sub-county Hospitals in Meru County. These findings concur with the findings of Umeano-Enemuoh, Onwujekwe, Uzochukwu and Ezeoke (2014) who examined patients' satisfaction of service delivery and care in tertiary institution in Southeast Nigeria. In their contribution, they aim to determine the factors which enhance and deter patients' satisfaction in a tertiary institution and service delivery and care. To do this, the study used a cross sectional survey design in which 360 carefully selected participants completed self-administered questionnaire to rate their satisfaction level, quality of services provided, as well as factors of importance where best service was provided. Overall, participants were quite satisfied (Mean score $=3.75$ ) with the services delivered by the different service providers. Equally, respondents also noted that the overall quality of care of the health facility was good (mean score $=3.45$ ). Pharmacy received the highest satisfaction level with a mean rating of 4.1. Over a third participants $(38 \%)$ rated the services provided by the doctors as best despite giving the highest quality ratings with a mean of 3.9 to pharmacy compared to mean ratings of 3.4 for the doctors.

Moreover, the findings also agree with the findings of Ogunfowokan and Mora (2012) who focused on the experiences of patients on time, expectation and satisfaction of service delivery. They determined the time spent by patients at the service points in the general Outpatient Departments (OPD) at the National Hospital Abuja (NHA), to establish the perception of patients regarding the patient-clinic encounter time, and to describe their level of satisfaction with the services received. A cross-sectional study was conducted at the general OPD of the NHA. Information which relate to the time spent at the various service points amongst others were obtained from 320 randomly selected patients, using a patient administered validated questionnaire. Nearly all (84\%) of the patients who responded adequately were identified and analysed. There was a significant relationship between a short waiting time as perceived by 
patients, clinic visit encounters where patients' expectations were met or surpassed, and overall patients' satisfaction with the clinic visit encounters. Based on the outcome of their results, they concluded that reduction in patient-clinic encounter time and meeting patients' pre-visit expectations may significantly improve patient satisfaction after clinic visit encounter at the general OPD of NHA.

Management practice such as "Management supervises staff adequately" was found to be very key for service delivery to patients. Meaning that when staff are well and adequately supervised, they are able to deliver services appropriately. This is after the aspect received the highest mean (Mean=3.86; $\mathrm{SD}=1.12$ ) compared to other aspects of management practices. This result is in agreement with the results of Sato et al., (2017), healthcare employees raised issues regarding compensation. For instance, in Uganda, health workers have raised concerns about poor remuneration relative to other civil servants of equitable professions. Providing opportunities for career development is considered the basis for promoting employee motivation in healthcare organizations. This encourages them to give their best towards achieving the changing medical needs for their communities (Momanyi, Adoyo, Mwangi \& Mokua, 2016). Moreover, according to Jooste \& Hamani, (2017), improved communication, introducing modern hospital facilities, improving working environments and providing proper water and sanitation systems are vital to ensuring employee motivation. Health workers' productivity and quality services can only be achieved in instances where there are safer and more pleasant working conditions (Deussom et.al, 2014).

\section{Conclusion}

The study found that the independent variable studied (management practices) had significant influence on service delivery at Sub-County Hospitals in Meru County. This shows that there was a strong and positive association between independent variable (management practices) and service delivery at Sub-County Hospitals in Meru County, Kenya as indicated by the p-value which was less than 0.05 at $95 \%$ confident level. The over-all of the p-value which was found to be less than $0.05(5 \%)$ is an indication of relevance of the studied variable significant at the $95 \%$ level of significant. This implies that the studied independent variable namely had significant influence on service delivery at Sub-County Hospitals in Meru County.

\section{Recommendations}

This study recommends that management should follow and adhere to hospital plans, motivation policy and lead by example to ensure smooth service delivery to the patients.

\section{References}

1. Ahumuza, S. E., Rujumba, J., Nkoyooyo, A., Byaruhanga, R., \& Wanyenze, R. K. (2016). Challenges encountered in providing integrated HIV, antenatal and postnatal care services: a case study of Katakwi and Mubende districts in Uganda. Reproductive Health, 13(41), 1-9. doi:10.1186/s12978-016-0162-8

2. Andaleeb, S. (2015). Service quality perceptions and patient satisfaction: A study of hospitals in a developing country. Social Science \& Medicine, 52(9), 135970 . doi:10.1016/S0277-9536(00)00235-5

3. Chodzaza, G., \& Gombachika, H. (2013). Service quality, customer satisfaction and loyalty among industrial customers of a public electricity utility in Malawi. International Journal of Energy Sector Management, 269-282. doi:10.1108/IJESM-02-2013-0003

4. Deussom, Drane, Bailey, \& Mehtsun. (2014). The Medical Education Partnership Initiative: Report of the Graduate Tracking Software Review and Implementation Workshop. intra health. 
5. Fiszbein, A., Ringold, D., \& Rogers, H. (2011). Making Services Work: Indicators, Assessments, and Benchmarking of the Quality and Governance of Public Service Delivery in the Human Development Sectors. Policy Research working paper; no. WPS 5690 Washington, D.C. : World Bank Group. Retrieved from http://documents.worldbank.org/curated/en /407281468176676618/Making-serviceswork-indicators-assessments-andbenchmarking-of-the-quality-andgovernance-of-public-service-delivery-inthe-human-development-sectors

6. Grönroos, C. (2007). Service Management and Marketing, $3 r d$ ed. . Delhi: John Wiley.

7. Jooste, K., \& Hamani, M. (2017). The motivational needs of primary health care nurses to acquire power as leaders in a mine clinic setting. Health SA Gesondheid. doi:10.4102/hsag.v22i0.961

8. Kim, A. J., \& Ko, E. (2012). Do social media marketing activities enhance customer equity? An empirical study of luxury fashion brand. Journal of Business Research, 65(10), 1480-1486. doi: 10.1016/j.jbusres.2011.10.014

9. Kotler, P. T., \& Keller, K. L. (2009). Marketing Management, 13th Edition. New York: Pearson.

10. Lenka, U., Suar, D., \& Mohapatra, P. (2010). Customer satisfaction in Indian commercial banks through total quality management approach. Total Quality Management and Business Excellence, 21(12), 1315-1341. doi:10.1080/14783363.2010.530773

11. Makheti, A. J. (2017). Technical Efficiency in Public Health Facilities in Meru County: Dea Analysis. Health Economics \& Outcome Research: Open Access, 3(4), 1-6. doi:10.4172/2471268X.1000143
12. Ministry of Health . (2014). Kenya Health Sector Referral Strategy. Nairobi: Division of Emergency and Disaster Risk Management.

13. Momanyi, G. O., Adoyo, M. A., Mwangi, E. M., \& Mokua, D. O. (2016). Value of training on motivation among health workers in Narok County, Kenya. Pan African Medical Journal, 23(261). doi:10.11604/pamj.2016.23.261.8414

14. Njuguna, J., Mwangi, P., \& Kamau, N. (2014). Incentives among health workers in a remote Kenyan district: implications for proposed county health system. Journal of health care for the poor and underserved, 25(1), 204-214.

15. Ogunfowokan, O., \& Mora, M. (2012). Time, expectation and satisfaction: Patients' experience at National Hospital Abuja, Nigeria. African Journal of Primary Health Care and Family Medicine, 4(1). doi:10.4102/phcfm.v4i1.398.

16. Sato, H., Niimi, A., Yasuhara, T., \& Permata, T. B. (2017). DNA double-strand break repair pathway regulates PD-L1 expression in cancer cells. Nature Communications volume. doi:10.1038/s41467-017-01883-9.

17. Umeano-Enemuoh, J. C., Onwujekwe, O., Uzochukwu, B., \& Ezeoke, O. (2014). Patients' Satisfaction and Quality of Care in a Tertiary Institution in Southeast Nigeria. Journal of Medicine. 